\title{
Breaking Bad News Revisited
}

Anne Arber, Faculty of Health \& Medical Sciences, University of Surrey

Ann Gallagher, The Open University 


\title{
Breaking Bad News Revisited
}

\begin{abstract}
This article revisits the ethical, legal, professional and emotional issues in disclosing bad news. We examine the push for disclosure as coming from a number of areas including ethical and legal challenges in particular the Bristol Royal Inquiry Report, professional codes of conduct, health policy and the expectations of the public. The contribution of nurses to the breaking of bad news appears to be invisible. With the development of new nursing roles and evidence based practice it is timely to consider the impact of nurses within the bad news process. We will highlight some limitations with guidelines for breaking bad news. In particular the limitation that bad news guidelines tend to be constructed from a professional standpoint with a lack of patient centred evidence. We also argue that bad news involves emotional labour and this concerns both professional staff and patients together. We conclude by discussing some of the practice implications regarding the breaking of bad news; the importance of context and continuity; the significance of information and support; desirable qualities of the professional; and issues to consider in determining patient preferences.
\end{abstract}

Key words: Breaking bad news, truth telling, communication, information and support 


\section{Introduction}

Those who work in the cancer and palliative care settings are committed to the principle of open communication of circumstances (Copp \& Field 2002). Despite the commitment towards more openness, health care practitioners continue to be troubled by the disclosure or withholding of difficult information, in relation to patients/clients. In this paper we survey contemporary ethical, legal, professional and psychosocial influences, which support the breaking of bad news. We will argue that there are omissions in the bad news literature. First, we will discuss how the breaking of bad news is a process rather than an event (Salander 2002). Secondly, we suggest that frameworks for breaking bad news appear to be constructed from a professional standpoint, rather than a patient/client standpoint (Butow et al 1996). Thirdly, we argue that there is inadequate attention to the emotional impact of bad news disclosure on the part of professionals and patients/clients (Smith \& Gray 2001, Ptacek \& Eberhardt 1996, James 1989). The result is a lack of empirical evidence regarding best practice in this area (Salander 2002, Ptacek \& Ptacek 2001). The nurse's role in the delivery of bad news is all but unknown as, until recently, the delivery of bad news is considered to be the role of medical staff (Dunniece \& Slevin 2000). Although some authors suggest that nurses may be well placed to deliver bad news as they are often the people patients feel most comfortable with (Higgins 2002, Faulkner 1998). Nurses themselves may not feel well prepared or comfortable with such a role (De Valck \& Van de Woestijne, 1996). We turn first to some definitions of bad news.

\section{What do we mean by bad news?}

One very simple definition of bad news is, that, it is information, which is perceived, from the eye of the beholder, to be in some way bad or unwelcome. A definition suggested by Buckman (1988) is that such news alters the patient's view of his/her future and is therefore considered bad. Ptacek and Eberhardt (1996) discuss how bad news is bad because it results in cognitive, behavioural, or emotional deficits in the person receiving the news and that this lasts beyond the bad news encounter. These deficits have implication for how the person will think, behave and feel in his/her response to the changes resulting from the news, in the short and longer term. Salander (2002:729) concludes that, rather than an event, 'bad news is better described as a process reflecting how physicians and hospital staff lived up to the patient's expectation of protection from the threat of danger to their lives'. The importance of the health care professional's knowledge of the patient, the relationship they have with the patient and the congruence achieved between the delivery 
of the bad news and the patient's individual needs are pivotal in the whole process. In acknowledging the bad news disclosure as a process rather than a one off event enables one to appreciate the role of members of the multidisciplinary team such as nurses, social workers as well as doctors. Aspects related to the nurse's role in bad news disclosures have been identified as monitoring the patient's awareness of his/her condition prior to disclosure of the cancer diagnosis and communicating this to the doctor (Morton 1996) and understanding the psychological needs of the patient following a diagnosis of cancer (Claxton 1993). Others such as May (1993) describe nurses as, 'practical mangers' of the events which follow disclosure, and also interpret medical information for patients and their families. Thus nurses have a key part to play in the process of disclosing bad news and providing support and information following such news. In the next section we examine some of the ethical, professional and legal drivers towards more openness and disclosure.

\section{What factors Drive Disclosure?}

i) The ethical, legal and professional environment

The push towards disclosure and openness can be characterised as ethical, legal and professional. From an ethical perspective, the movement towards disclosure can be framed in terms of the trumping of autonomy over paternalism. There continues to be debate in healthcare about the ethical implications of the giving and withholding of information. Should patients/clients be told the truth, the whole truth and nothing but the truth? When, if ever, is it justifiable to withhold information?

Field \& Copp (1999) discuss the movement from the 'closed' awareness toward 'openness' between the 1960s and the 1980s and another shift from 'openness' to 'conditional openness' on the part of doctors during the late 1980s and 1990s. They argue that specialists in palliative care have adopted a more 'conditional' approach to disclosing terminal prognoses, as indicated by use of terms such as 'titrated' or graduated dosages of truth. They conclude that despite a commitment to 'open awareness' doctors and nurses retain their control over information and its disclosure. This suggests that there may be some ambiguity and uncertainty around how open one should be. Indeed in a comprehensive survey of 65,000 cancer patients thirteen per cent believed that at least on one occasion doctors or nurses deliberately withheld information from them (DOH 2002).

Arguments to support truth telling are generally justified on the basis of patient autonomy. 
Whilst there is no consensus as to what autonomy involves, a common view is as presented here:

To respect an autonomous agent is, at a minimum, to acknowledge that person's right to hold views, to make choices, and to take action based on personal values and beliefs. Such respect involves respectful action, not merely a respectful attitude. It also requires more than obligations of non-intervention in the affairs of persons...it includes obligations to maintain capacities for autonomous choice while allaying fears and other conditions that destroy or disrupt their autonomous actions.

(Beauchamp \& Childress 2001:63)

On this account, patients as autonomous individuals have a right to information, including bad news, as this enables the individual to act autonomously and to engage in decision-making about their care even when choices are limited. However, respect for autonomy needn't imply that all of the information is given all of the time. An argument based on autonomy might also be presented to defend a right not to know:

Health professionals should always inquire in general terms about their patients' wishes to receive information and to make decisions, and they should never assume that because a patient belongs to a particular community, he or she affirms that community's world view and values... Respect for autonomy is not a mere ideal in health care; it is a professional obligation. Autonomous choice is a right, not a duty of patients. (Beauchamp \& Childress 2001:63)

The importance of not making assumptions about what people may wish to know is evident in the above quote. Bad news tends to be conceptualised from the perspective of the dominant western culture. However, cultural differences exist and there may be cultural rules and taboos related to disclosure. Thus, respect for autonomy may also justify a right not to know. Arguments to support the withholding of negative information are commonly justified on the basis of beneficence (doing good) and paternalism. The issue of informed consent is pertinent here also. Traditionally, informed consent has been applied to treatment considered invasive rather than diagnosis (Rudnick 2002 p.62) or the receipt of other information. This is a challenging area. As Rudnick (ibid p.63) says:

Logically, there is an apparent paradox inherent in obtaining informed consent to breaking or waiving bad news; one has to suggest the possibility of bad news to the patient, hence implying bad news, and thus perhaps breaking bad news - albeit without diagnostic details - in the process of obtaining informed consent for that. 
Obtaining informed consent prior to the breaking of bad news is undoubtedly challenging but these challenges are not insurmountable. It should be possible to engage in a dialogue with the patient, from admission, regarding their preferences in relation to information.

From a legal perspective, there is no right to full disclosure in relation to consent concerning the nature and risks of treatment (Gallagher \& McHale 2001). The introduction of the Human Rights Act 1998 would appear to bolster the right to autonomy and to non-discrimination in relation to this right. The Human Rights Act defines the right to respect for private and family life (Article 8) and prohibition of discrimination (Article 14). A challenging issue arises should a patient decline information. Their agreement to related interventions cannot then be said to be informed. The importance of informed consent generally drives the decision to give all material information relevant to that patient and his/ her medical condition. If patients/clients are not given necessary information, then there may be negligence claims in the future. As with other healthcare interventions, patient should have time to consider whether to accept or decline bad news or other information relevant to their care and a summary of the discussion with professionals should be documented

ii) The professional environment: codes of conduct

The professional impetus towards disclosure (although, it should be said, not specifically in relation to bad news) is evident in recent health policy documents and in the Codes of health care professionals (Nursing and Midwifery Council 2002, DOH 2002, The NHS Cancer Plan 2000). The General Medical Council document 'Good Medical Practice' (1998) states that doctors must:

give patients the information they ask for or need about their condition, its treatment and prognosis...give information to patients in a way they can understand.

The Nursing and Midwifery Council (NMC) Code of Professional Conduct states:

$$
\begin{aligned}
& \text { All patients have a right to receive information about their condition. You must be } \\
& \text { sensitive to their needs and respect the wishes of those who refuse or are unable to } \\
& \text { receive information about their condition. Information should be accurate, truthful } \\
& \text { and presented in such a way as to make it easily understood. (NMC 2002, Section 3.1) }
\end{aligned}
$$

Clearly, there is support for autonomy and the right to information and it is also acknowledged that there is a right to refuse such information. One of the challenges here is in recognising 
patient's needs and wishes. Therefore skill in eliciting patient's readiness for information and their wishes in relation to being involved in decision-making is important (Effective Health Care 2000). The framework discussed in the next section is helpful here.

\section{Framework for Breaking Bad News}

A number of authors have devised guidelines to help practitioners meet patient's needs in a sensitive and practical manner, undoubtedly this is a very helpful reminder of important actions in the breaking of bad news (Buckman 1992, Girgis \& Sanson-Fisher 1995). Kaye (1996) suggests a 10-step approach to breaking bad news, which involves:

$\circ$ preparation (find out relevant facts before the meeting);

- what does the patient know? (finding out by asking for narrative);

$\circ$ is more information wanted? (check how much patient wants to know);

$\circ$ give a warning shot;

- allow denial;

$\circ$ explain (if requested);

- listen to concerns;

- encourage ventilation of feelings (described as 'KEY phase');

- summary-and-plan (which includes fostering hope); and

- offer availability.

There is no doubt that these steps are helpful but they are also raise questions. The role of emotions in the giving of bad news, as opposed to the receiving of such news, is not made explicit within the guidelines. Kaye's steps point to the breaker of bad news finding out how much the patient/client wants to know. Although this may sound very straightforward, a situation may arise where there is a discrepancy between what the professional believes the patient needs to know and what s/he may want to know at this particular time. Professionals 
also need to be sensitive to what the patient is trying to tell them. For example, in a study of three patients' and their physician it was found that individual patients may resist being given bad news by being silent or introducing competing topics and in doing so they derailed the doctors efforts to deliver the bad news, irrespective of the doctor's skill in delivery ( Lutfey \& Maynard 1998). Patients may also become aware of how the professional may adopt a technique such as that of gradual disclosure and begin to understand when to expect such news on a gradual basis. John Diamond (1998) described how he became aware that professionals use a strategy of 'gradual disclosure'. He explains how he was told he was going to receive a course of radiotherapy and a couple of days later a registrar described how he would lose hair round the radiotherapy site. Sometime later he was told he needed a dental check and how he would need to rub fluoride gel into his gums, not just for now, but for the rest of his life. This leads one to conclude that patients may pick up cues and patterns of behaviour unintentionally communicated by the professional and make assumptions on that basis.

Miyaji (1993) carried out an interview study with 32 physicians in a hospital in the United States. The researcher was interested in physicians' views of their practice regarding truth telling and their ethical standpoints. He describes how these doctors tell terminally ill patients about their diagnosis and prognosis in terms of the patients desires to know and based on a belief related to patient rights and autonomy. However, if patients don't ask, the doctor may interpret this as an indication that the patient does not want to know. A number of patients in Costain Schou \& Hewison's (1999) study described their reluctance to question their doctor and find out more while simultaneously talking about their fears, guesses and interpretations of how ill they were to the researchers. Anne-Mei The (2002) also identifies the rule used by doctors in her study of patient's with lung cancer, of adjusting what is said to what is asked. The reasons discussed above may account for why patients may talk to non-threatening people like student nurses, health care assistants and researchers about their concerns and worries as they fear what they may hear from doctors and other senior health care professionals. This brings us to the emotional labour involved in bad news disclosures.

\section{Disclosure and Emotions}

Bad news is disclosed in a medical and psychosocial context within a relationship and results in the patient having to adapt to the changes associated with the news. These changes involve 
an emotional reaction and adjustment whether this is made visible through behaviour or remains invisible or private. A range of emotions may be experienced in relation to the breaking of bad news, most significantly, anger, guilt and fear (Faulkner 1998 p.49).

Salander (2002) points to a tendency to reduce the patient-physician relationship in bad news guidelines to 'an event of transmittance of information between an active sender (physician) and a passive receiver (patient)'. Salander argues that 'a helping relationship precedes information'. What this involves is not made explicit but it seems to us that it may approximate to what Campbell (1984) refers to as 'skilled companionship'. While Campbell is primarily concerned with the relationship between the nurse and the patient, it seems that this can apply to all professionals working in cancer and palliative care contexts. He writes:

'...It is a bodily presence which accompanies the other for a while. The image of a journey springs to mind when we think of the companion. Companionship arises often from a chance meeting and it is terminated when the joint purpose which keeps companions together no longer obtains. The good companion is someone who shares freely, but does not impose, allowing others to make their own journey.....Nursing is a companionship which helps the person onward. Whether the destination is recovery or death a companion helps the hardness of the journey. So the good companion looks ahead and encourages when all seems lost...'(Campbell 1984:49)

In confronting the 'hardness of the journey', which involves the breaking of bad news, there is an emotional cost. Professionals for example have to manage their own emotions in the breaking of bad news and patients have to deal with the emotional implications of receiving it (Ptacek \& Eberhardt 1996). Dunnice and Slevin (2002) in an interview study involving 6 staff nurses found that nurses described how they experienced distress, such as helplessness and anger, during bad news disclosures by 'being there' with the patient. The researchers found that this distress was heightened if they perceived that medical staff employed a poor method of disclosure. In other situations, when bad news goes wrong, nurses may find themselves 'picking up the pieces' and engaging in 'emotional labour' to attend to the patient's anger and distress (Higgins 2002).

'Emotional labour' has been defined as 'the labour involved in dealing with other peoples' feelings' (James 1989) and as the 'induction or suppression of feeling in order to sustain in others a sense of being cared for in a convivial safe place' (Smith \& Gray 2001 referring to work of Hochschild 1983). Research highlights the importance to patients of feeling cared for - represented by the personal qualities of medical staff, including kindness, considerateness, trustworthiness, empathy - with how the patient is feeling. A warm and caring tone (Salander 2002, Ptacek \& Ptacek 2001) as well as physician expertise and information giving on 
treatment options are identified as crucial (Parker et al 2001). Kaye advises encourage ventilation of feelings this may be a stressful step for the physician. Ptacek \& Eberhardt (1996) suggest that the giver of the news may feel as much stress as the person receiving the news during the transaction. The emotional labour of breaking bad news is a shared experience between two people and is mediated by the sense of a relationship and taking care in a 'convivial safe place'. The emotional labour around bad news, we suggest, is invisible work that goes unremarked and unrecorded. Nurses' involvement in the breaking of bad news calls for emotional labour, particularly if they have to 'pick up the pieces' when bad news has gone badly (May 1993).

Kaye (1996) discusses preparation for giving bad news and preparing the patient by giving a verbal warning shot that bad news is about to be given. This enables psychological preparation for the patient in relation to what they are about to hear. The use of a warning shot has been found to enhance patient satisfaction (Ptacek \& Ptacek 2001). Patients also have to pass on the bad news to family and friends and this has an emotional cost also. John Diamond describes how he never found a completely satisfactory way to pass on news of his cancer diagnosis to friends and work colleagues. In addition to professionals managing their emotions, patients, also have to engage in responding to the feelings of others and John Diamond describes his discomfort at the reactions of others to his cancer diagnosis. These many dimensions of the telling and re-telling of bad news is an area worthy of further investigation.

\section{Practice Implications}

\section{i) Providing Context and continuity}

Research evidence from a patient perspective support the view that patients have a right to decide who should be present when the news is given, with about half of patients wishing to have a spouse present when the news was disclosed (Butow 1996, DOH 2002). Butow et al (1996) also suggests that it is important to discuss with the patient their wishes regarding the presence of staff other than the person giving the news. If it is necessary to have staff present it should be made clear what their role is and consent for their presence sought. The Kings Fund recommend that patients should document who has told them the news and have contact numbers of people who can provide further information (Walker et al 1996). This may be delegated, for example, to a specialist nurse or ward sister. In a comprehensive survey of 65,000 cancer patients involving 170 trusts in 1999 to $2000,91 \%$ of patients had been given the name of the doctor in overall charge of their care but only $47 \%$ reported that they had been given the name of a nurse in a similar role (DOH 2002). The recent Bristol Royal Infirmary 
Inquiry, recommends that patients should always be given the opportunity and time to ask questions about what they are told, to seek clarification and to ask for more information. It is worrying therefore that many patients with cancer do not always have the name of a nurse who could provide continuity of care.

\section{ii) Support and Information}

Research evidence supports the importance of giving details of information services and support groups to those receiving a diagnosis of cancer (National Cancer Alliance 1996). This type of practice is variable and seems to vary across cancer site according to the Department of Health survey (2002) as only $31 \%$ of men with prostate cancer were given such information compared to $68 \%$ of women with breast cancer in this study. Kennedy supports the need for information about treatment and care to be given in a variety of forms, be given in stages and be reinforced over time. In some contexts nurses have identified the importance of interpreting medical information for patients, and listening and answering questions (Dunnice \& Slevin 2002, May 1993). The Commission for Health Improvement (2001) identify how access to a variety of media including booklets, videos and the World Wide Web was sought by patients. It is therefore important that patients know where they can get such information and in addition whom they can contact so that information is tailored to individual needs, circumstances and wishes.

Some authors advocate the tape recording of the consultation so that it can be listened to at home and this has been well received by patients (Tattersall et al 1994, Kennedy 2001). What is delivered by the health care professional may not be interpreted and received in the same way by the patient. Training in how to implement the tape recording of consultations should be explored in post qualification courses in communication skills (Department of Health 2000).

\section{iii) Qualities of the Professional \& emotional labour}

Qualities such as kindness and compassion are considered important from the patient's perspective (Salander 2002). One conveys these qualities through not being kept waiting and by giving time (Salander 2002); using language that the person can understand and avoiding confusing terminology (Yardley et al 2001, Buckman 1992); by consideration and respect for dignity (DOH 2002); by attention to privacy, away from interruptions and being seated in a comfortable space (Ptacek \& Ptacek 2001, Kaye 1996). Patients appreciate these qualities at this vulnerable time as they help to preserve self-respect and dignity. We would also add 
sensitivity to cultural differences and belief systems related to the disclosure of bad news. There is evidence of inadequacies in how people from ethnic minorities experience cancer services - in particular being treated with respect and dignity (DOH 2002).

\section{iv) Assessing patient preferences}

One way of individualising care at this difficult time is to assess and discuss patients preferences regarding care and information-giving in relation to diagnosis, prognosis, treatment and support. This would enable one to incorporate the principle of autonomy, consent and respect for human rights. Patients need time to think, in a safe supportive context, about how they would like information disclosed, whom they would like to be present and to support them and what their expectations of staff are, before they are in a position to be receiving such news. Nurses, we would argue, have a key role to play in ascertaining patient preferences and enabling the patient to communicate those preferences and therefore provide continuity at this time.

Finally, guidelines should stress the variability in patient preferences (Butow et al 1996) and the need for flexibility in relation to differences and diversity in bad news contexts. They should also identify support structures for the patient, but also for those engaged in such work. With highly skilled nurses taking on new roles the time is now right to revisit breaking bad news and negotiate a new order. Thus nurses as members of the multidisciplinary team can negotiate their role in the breaking of bad news and become accountable for that work. The expertise involved in breaking bad news concerns medical expertise as well as knowledge of the individual patient and interpersonal skills. A negotiated approach to the breaking of bad news is in tune with the more flexible approach to professional boundaries and this is supported by the policy context (Department of Health 2002, 2001, 1999).

\section{CONCLUSION}

We suggest that the time is right for a re-evaluation of the process of bad news disclosure. We have discussed some of the factors which continue to drive disclosure in healthcare. Most significantly, support for the principle of autonomy which supports both a right to know and a right not to know. There is also a legal and professional impetus to disclose information to patients. It was acknowledged that decisions to waive information may post challenges to professionals. Both GMC and NMC professional codes also support the sharing of information. Kaye's 10 stop approach was introduced and it was pointed out 
that, whilst it is helpful to have such a framework, it underplays the role of the emotions. Emotional labour is highlighted as an important component of the breaking bad news process. Patients may also have to engage in emotional labour in breaking bad news to friends and family and this is little acknowledged. Given changes in nurses' roles, it seems inevitable that they will be increasingly involved in this most challenging and important aspect of care. How the division of work involved in breaking bad news is negotiated, in different contexts, is an interesting area for further research. This would provide useful information about what actually happens in practice rather than what is reported to have happened. Further research would also build an evidence base of nurse's contribution to the process (Dunnice \& Slevin 2000). Finally, the emotional labour of the health care professional should be acknowledged. Therefore support and feedback in the context of breaking bad news becomes part of medical and nursing culture so that, as far as possible, empathy and compassion are maintained. 


\section{References}

Beauchamp T.L. \& Childress J.F. (2001) Principles of Biomedical Ethics Oxford University Press

Buckman R. (1992) How to Break Bad News. London Papermac

Buckman R. (1988) I don't know what to say. London, Macmillan

Butow PN., Kazenu JN., Beeney LJ., Griffin A-M., Dunn SM \& Tattersall MHN (1996) When the Diagnosis is Cancer patient Communication and Preferences. Cancer, 77,12, Pg. 2630-2637

Campbell A. V. (1984) Moderated Love - A Theology of Professional Care SPCK, London

Claxton JW (1993) Paving the way to acceptance: psychological adaptation to death and dying in cancer. Professional Nurse, 6 206-211

Commission for Health Improvement/Audit Commission (2001). National Service Framework Assessments. No. 1: NHS cancer care in England and Wales. London CHI/AC.

Copp G \& Field D (2002) Open Awareness and dying; The use of denial and acceptance as coping strategies by hospice patients. Nursing Times Research,7,2 Pg. 118-127

Costain Schou K \& Hewison J (1999) Experiencing Cancer, Buckingham, Open University Press

Department of Health (2002) National Surveys of NHS Patients: Cancer National Overview 19992000. Department of Health, London

Department of Health (2000) A Health Service of all the Talents. Developing the NHS Workforce. Department of Health, London

Department of Health (2000) The NHS Cancer Plan: a plan for investment, a plan for reform. Department of Health, London

Department of Health (1999) Making a difference strengthening the nursing, midwifery and health visiting contribution to health. and healthcare. Department of Health, London 
De Valck C \& Van de Woestijne KP (1996) Communication problems on an oncology ward. Patient Education and Counselling 29, Pg 131-136

Diamond J. (1998) C-Because cowards get cancer too... Vermillion, London

Dunniece U \& Slevin E. (2000) Nurses' experiences of being present with a patient receiving a diagnosis of cancer. Journal of advanced Nursing 32,3 Pg 611-618

Effective Health Care (2000) Informing, communicating and sharing decisions with people who have cancer. NHS Centre for Reviews and Dissemination, The University of York

Faulkner A (1998) ABC of palliative care: communication with patients, families, and other professionals. British Medical Journal, 316 Pg 130-132

Faulkner A. (1998) When the news is bad: A guide for health professionals Stanley Thornes Publishers Ltd, Cheltenham

Field D. \& Copp G. (1999) Communication and awareness about dying in the 1990s. Palliative Medicine, 13, pg 459-468

Gallagher A. \& McHale J. (2001) After Bristol: the importance of informed consent Nursing Times Vol. 97 , No.49, pp. 32-34

General Medical Council (1998) Good Medical Practice GMC, London

Girgis A \& Sanson-Fisher W (1995) Breaking Bad News: Consensus Guidelines for Medical Practitioners. Journal of Clinical Oncology, 13,9 Pg. 2449-2456

Human Rights Act (1998) HMSO, London

Higgins D (2002) Breaking bad news in cancer care. Part 2: practical skills. Professional Nurse, 17,11 Pg 670-671

Hochschild AR (1983) The Managed Heart: The Commercialization of Human Feeling. University of California Press, Berkeley, CA 
James N. (1989) Emotional labour: skill and work in the social regulation of feelings Sociological Review Vol. 37, No. 1, pp.15-42

Kaye P. (1996) Breaking Bad News A 10 Step Approach. EPL Publications Northampton

Kennedy I. et al (2001) The Inquiry into the Management of Care of Children Receiving Complex Heart Surgery at the Bristol Royal Infirmary The Stationary Office, London

Lutfey K \& Maynard DW (1998) Bad News in Oncology: How Physician and Patient Talk about Death and Dying without Using Those Words. Social Psychology Quarterly, 61,4 Pg. 321-341

May C (1993) Disclosure of terminal prognoses in a general hospital: the nurse's view. Journal of Advanced Nursing 18, Pg 1362-13568

Maynard DW (1996) On 'Realization' in everyday life: The forecasting of bad news as a social relation. American Sociological Review, 61 Pg 109-131

Meier D.E., Back A.L. \& Morrison R.S. (2001) The Inner Life of Physicians and Care of the Seriously Ill JAMA Vol 286, No. 23 pp.3007-3103

Miyaji NT (1993)The power of compassion. Truth telling among American doctors in the care of dying patients. Social Science and Medicine 36,3 Pg. 249-264

Morton R (1996) Breaking bad news to patients with cancer. Professional Nurse 11, Pg 669671

National Cancer Alliance (1996) Patient Centred Cancer Services: What Patients Say. Oxford, National Cancer Alliance

Nursing and Midwifery Council (2002) Code of Professional Conduct NMC, London

Parker PA, Baile WF, de Moor C, Lenzi R, Kudelka AP \& Cohen L (2001) Breaking Bad News about Cancer: Patients' Preferences for Communication. Journal of Clinical Oncology, 19,7 Pg. 2049-2056

Ptacek JT \& Eberhardt TL (1996) Breaking Bad News: A Review of the Literature. Journal of the American Medical Association, 276, Pg. 496-502 
Ptacek JT \& Ptacek JJ (2001) Patients' Perceptions of Receiving Bad News about Cancer. Journal of Clinical Oncology, 19,21 Pg. 4160-4164

Ptacek JT, Fries EA, Eberhardt TL \& Ptacek JJ (1999) Breaking bad news to patients: physicians' perceptions of the process. Supportive Care in Cancer 7,3 Pg. 113-120

Rudnick A (2002) Informed Consent to Breaking Bad News. Nursing Ethics, 9,1 Pg 61-66

Salander P (2002) Bad news from the patient's perspective: an analysis of the written narratives of newly diagnosed cancer patients. Social Science \& Medicine 55,5 Pg. 721-732

Smith P. \& Gray B. (2001) Emotional labour of nursing revisited: Caring and Learning 2000 Nurse Education in Practice Vol. 1, pp.42-49

Tattersall MN,Butow PN,G riffin AM \& Dunn SM(1994) The take-home message: Patients prefer consultation audiotapes to summary letters. Journal of Clinical Oncology,12,Pg.1305-1311

The A-M (2002) Palliative care and communication. Buckingham, Open University Press

Walker G., Bradburn J. \& Maher J. (1996) Breaking Bad News. The Kings Fund, Kings Fund Publishing, 11-13 Cavendish Square, London W1M OAN

Yardley SJ, Davis CL \& Sheldon (2001) Receiving a diagnosis of lung cancer: patients' interpretations, perceptions and perspectives. Palliative Medicine, 15 Pg 379-386 